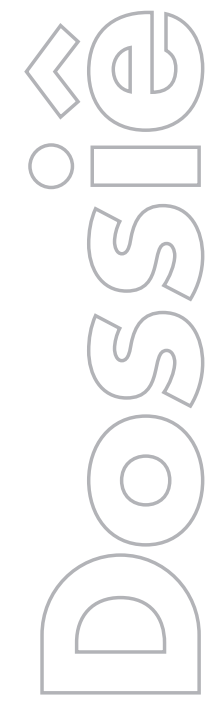

revista

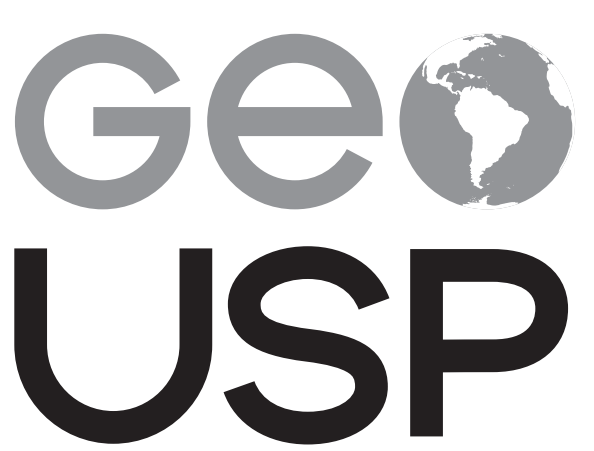

espaço e tempo

Volume $22 \cdot n^{\circ} 3$ (2018)
Pensar radicalmente sob a repressão: a geografia crítica brasileira no contexto da ditadura civil-militar

\section{Elisa Favaro Verdi} USP

p. $539-558$

Como citar este artigo:

VERDI, E. F. Pensar radicalmente sob a repressão: a geografia crítica brasileira no contexto da ditadura civil-militar. Geousp - Espaço e Tempo (Online), v. 22, n. 3, p. 539-558, dez. 2018. ISSN 2179-0892.

Disponível em: <https://www.revistas.usp.br/geousp/article/view/152423>. doi: http://dx.doi.org/10.11606/issn.21790892.geousp.2018.152423.

\section{(C) $(1)(\$$}

Este artigo está licenciado sob a Creative Commons Attribution 4.0 License. 


\title{
Pensar radicalmente sob a repressão: a geografia crítica brasileira no contexto da ditadura civil-militar
}

\section{Resumo}

O objetivo deste artigo é analisar o contexto sócio-histórico do desenvolvimento da chamada Geografia Crítica brasileira. $\bigcirc$ movimento se desenvolve no momento da ditadura civil-militar, um período de autoritarismo e repressão política, social e intelectual. Assim, o questionamento que move esta reflexão é no sentido de compreender como um pensamento crítico - a Geografia Crítica - se fortalece e prolifera num momento de repressão. Para tanto, tratamos do processo de modernização autoritária que o regime militar implementou, com especial interesse na modernização do ensino superior e em suas consequências na Universidade de São Paulo (USP), mais especificamente na Faculdade de Filosofia, Letras e Ciências Humanas (FFLCH). A intenção é compreender as possíveis relações entre esse contexto e a elaboração de novos temas e problemáticas na ciência geográfica a partir dos sujeitos diretamente envolvidos nessa elaboração: os estudantes de graduação e pós-graduação em Geografia à época.

Palavras-chave: Geografia crítica. Ruptura crítica. Ditadura civil-militar. Modernização autoritária. Universidade de São Paulo.

\section{Think radically under repression: the Brazilian Critical Geography in the context of the civil-military dictatorship}

\begin{abstract}
The objective of the present article is to analyze the socio-historical development context of the so-called Brazilian Critical Geography. Such movement occurred in the moment of the civil-military dictatorship, a period of authoritarianism and political, social and intellectual repression. Therefore, the questioning that moves this reflection is to understand how critical thinking -in this case, Critical Geography - is strengthened in a moment of repression. To that end, we will analyze the
\end{abstract}


authoritarian modernization that the military regime has implemented, with special interest in the modernization of higher education and consequences for USP, more specifically for FFLCH. The intention is to understand the possible relationships between such context and the elaboration of new themes and problems in geographic science, from the point of view of the subjects directly involved in this elaboration: undergraduate and postgraduate students in Geography at the time.

Keywords: Critical Geography. Critical rupture. Civil-military dictatorship. Authoritarian modernization. University of São Paulo.

\section{Introdução}

Refletir sobre a atualidade da Geografia Crítica, desafio posto pelo Seminário 40 anos da Geografia Crítica, que suscitou o presente artigo, é um momento oportuno para retomarmos os questionamentos e o contexto que moveram a elaboração da Geografia Crítica, compreendida aqui como um movimento de ruptura metodológica e política com uma Geografia - retrospectivamente - chamada de tradicional. Remontar às questões e reconstruir o contexto da década de 1970 significa retornar a um momento da história do Brasil em que vivíamos sob uma ditadura e que o conhecimento era produzido sob repressão e ameaça - inclusive a Geografia Crítica produzida pelo Departamento de Geografia da Universidade de São Paulo (USP), caso que será aqui analisado.

Assim, é fundamental voltar s esse momento por dois motivos principais: primeiro, e mais evidente, a situação política em que o país se encontra hoje, quando nos deparamos com a ascensão do fascismo e, com ele, a escalada da violência, cuja representação máxima é a figura do presidente eleito Jair Bolsonaro; segundo, a necessidade de pensarmos sobre a relação entre o movimento do pensamento e o movimento da realidade, ou seja, sobre as exigências que a realidade impõe aos que nos propomos a desvendá-la.

Antonio Candido argumentou que "investigar os traços de um pensamento radical é condição indispensável para o exercício adequado e eficiente das idéias de transformação social" (Candido, 1990, p. 4). Nesta exposição, o objetivo será remontar os traços políticos da construção de um pensamento radical - a Geografia Crítica - durante um período de repressão. Para tanto, trataremos do processo de modernização autoritária que o regime militar implementou, com especial interesse na modernização do ensino superior e consequências para a USP, mais especificamente para a Faculdade de Filosofia, Letras e Ciências Humanas (FFL$\mathrm{CH}$ ). A intenção é compreender as possíveis relações entre esse contexto e a elaboração de novos temas e problemáticas na ciência geográfica, a partir dos sujeitos diretamente envolvidos nessa elaboração: os estudantes de graduação e pós-graduação em Geografia à época.

As informações que serão aqui expostas encontram-se principalmente em relatos de professores da FFLCH publicados depois do fim da ditadura; em documentos da Associação dos Docentes da USP (Adusp); em entrevistas e memoriais de concurso dos então estudantes e atualmente professores do Departamento de Geografia. 


\section{AGB, 1978: gênese ou fundamento da Geografia Crítica?}

Para diversos autores que realizaram análises e balanços do processo de renovação da Geografia brasileira, como Ruy Moreira, Ariovaldo Umbelino de Oliveira e Carlos Walter Porto-Gonçalves, entrevistados por Paulo Cesar Scarim (2000), além do próprio Scarim, entre outros, o Encontro Nacional de Geógrafos da AGB realizado na cidade de Fortaleza em 1978 é um marco na história da Geografia Crítica no Brasil. Segundo Mamigonian (1991), esse evento definiu um momento de renovação da entidade que foi fruto de uma radicalização do movimento estudantil da Geografia. De acordo com Moreira (in Scarim, 2000), a AGB foi até os anos 1970 uma entidade acadêmica que reunia a "oligarquia" dos departamentos de Geografia nas mais diversas universidades brasileiras. Nesse quadro, os estudantes, que eram também professores do ensino básico, ${ }^{1}$ dispararam um processo de democratização da entidade, processo que determinou os rumos da AGB reformulando suas bases e objetivos. $\mathrm{Na}$ mesma entrevista, esse autor afirma que o evento de 1978 marca a abertura democrática da entidade, desencadeada pelos estudantes:

[... ] 78, o terceiro encontro da AGB, foi aquele marco de mudança da Geografia no Brasil. Foi como que, os vários grupos até então clandestinos na Geografia, análogos aos grupos que eram clandestinos na política e na sociedade brasileira, que saindo da clandestinidade, com a sociedade abrindo-se um pouco mais democraticamente, eles vieram à tona, se apresentaram e disseram aqui estamos nós. [...] A força do encontro de 78 em Fortaleza veio exatamente desta movimentação, deste rio subterrâneo, e não das academias (Moreira in Scarim, 2000, p. 107).

Para Porto-Gonçalves (in Scarim, 2000), o movimento de 1978 deve ser compreendido no contexto de transformação das universidades no Brasil. A expansão do ensino superior nos anos 1960-70 foi responsável pela entrada nas universidades públicas de alunos cuja origem social era a classe operária. Nesse contexto, a AGB, que se mantinha como uma instituição elitista e restrita, passou por um processo de renovação que ampliou seu quadro de associados: "A universidade fica uma coisa ampliada e a AGB continua sendo uma coisa restrita, tinha sócio titular, que tinha que passar por todo um peneiramento, então era muito longe dos estudantes, muito longe e muito restrita" (Porto-Gonçalves in Scarim, 2000, p. 74).

Assim, para esses autores, o encontro de 1978 foi o momento em que os estudantes - majoritariamente - que desejavam uma outra entidade se encontraram, iniciando um movimento sem centralismo que reivindicava uma Geografia preocupada com a transformação social. A partir desses autores, entende-se que se tratou de um movimento difuso, que ousava uma crítica ao positivismo dentro da Geografia, mas que tinha um sentido de pertencimento, pois reivindicava uma maior participação e abertura da entidade representativa dos geógrafos (Scarim, 2000; Verdi, 2016).

1 Vesentini $(1985,1988)$ argumenta que o movimento de crítica à Geografia foi protagonizado por professores do ensino básico, os quais eram também estudantes de pós-graduação que, refletindo sobre sua própria prática, renovaram a disciplina. Tal interpretação pode ser atribuída à própria experiência do autor como professor no curso supletivo do sindicato dos metalúrgicos de São Bernardo do Campo e Diadema, no estado de São Paulo, em meados da década de 1970. Nessa ocasião, conforme relata em memorial, Vesentini reproduziu não apenas o conteúdo usual, mas também textos e debates sobre distribuição de renda, direito de greve, papel dos sindicatos, lutas operárias, degradação ambiental, capitalismo e democracia (Vesentini, 1988). 
No entanto, esse conflito que se evidenciou em 1978, entre uma perspectiva positivista e outra crítica, já havia aparecido antes no interior da AGB. Em entrevista concedia a mim para o mestrado (Verdi, 2016), o professor Ariovaldo U. de Oliveira relatou a experiência de um dos primeiros conflitos entre as perspectivas tradicional e quantitativa e uma perspectiva crítica, nesse caso marxista, no Encontro Nacional de Geógrafos de 1976:

O encontro de Belo Horizonte foi o encontro do embate entre alguns geógrafos marxistas, porque eram poucos, e os empiristas lógicos. Isso tudo foi canalizado na apresentação do Armen [Mamigonian], no último dia. Começou um movimento dentro do encontro dos empiristas lógicos para fazer a crítica ao Armen, e eles elegeram o Roberto Lobato [Correa] para ser o que ia falar. $\bigcirc$ Lobato tinha acabado de fazer o mestrado nos Estados Unidos, tinha chegado de volta fresquinho com as ideias empiristas lógicas bastante fundamentadas. [...] Bem, então foi se criando um clima de oposição. E aí na apresentação, o Armen fez a apresentação dele, maravilhosa. Primeiro geógrafo brasileiro marxista, apesar de não aparecer no doutorado dele. [...] Ele terminou a fala dele e ninguém aplaudiu. O Lobato pediu a palavra e começou a criticar. Ele usou uma estratégia de fala, discursiva, que era assim: "se você tivesse sido marxista, você teria falado..." e começou a falar lá, a leitura empirista lógica do marxismo. "Se você fosse historicista, você teria feito isso. Se você fosse empirista lógico, você teria feito isso". Em outras palavras: o Armen era um empiricista, não tinha teoria na apresentação dele. Quando o Lobato terminou, depois de falar quase meia hora, o pessoal do IBGE que estava na frente, no salão enorme lá na UFMG, aplaudiu o Lobato até não querer mais. Aí o sangue subiu nas veias, como a gente diz, de forma caipira, e eu pedi a palavra. Fiz uma intervenção dizendo: "olha, senhor Lobato, acho que o senhor não viu que na apresentação do professor Armen tinha isso...", aí fui fazendo um diálogo com o Lobato e ao mesmo tempo mostrando o que de análise marxista tinha na apresentação do Armen. Fiz a minha fala, ficou aquele silêncio sepulcral porque é a intervenção fora do script. Aí em seguida o Manuel Correia [de Andrade] pediu a palavra e também elogiou o Armen. Depois dessas falas, a palavra foi pro Armen, e ele disse: "Lobato, não preciso mais me defender porque o Ariovaldo e o Manuel Correia já me defenderam. Então, eu vou apenas fazer uma resposta curta para você. E como você é carioca, vou usar uns versos do Noel Rosa!", e aí ele canta: "Quem é você, que não sabe o que diz? Meu Deus do Céu, que palpite infeliz" (Oliveira, A., in Verdi, 2016, p. 34).

Nota-se que esse relato evidencia a existência de um conflito entre as perspectivas que se realizava na AGB, lugar de diálogo, divergência e confronto das diferenças. Percebe-se, assim, que a ação política interna à disciplina se canalizava também na $A G B$ e nos seus encontros, como este de 1976 e no seguinte, emblemático, de 1978.

Argumenta-se aqui, coetaneamente aos autores já citados, que a renovação crítica na ciência geográfica é muito mais ampla do que o movimento de 1978. Não cabe discordar de que este momento foi fundamental para a renovação e que sua importância e magnitude o 
constituam em um marco da renovação mesma. Entretanto, o entendimento do processo de renovação não deve restringir-se ao marco, e por isso o objetivo da análise deve ser compreender a renovação crítica justamente como um movimento tanto anterior quanto posterior ao encontro de 1978, que o inclui como parte de um processo mais amplo.

Procura-se também compreender esse processo de renovação não por ele mesmo, a partir de uma perspectiva internalista (Machado, 2000), mas em relação e inserido em seu contexto histórico. De acordo com Peet (1982), a renovação da Geografia nos EUA se deu justamente em um período de transformações sociais profundas que exigiram das ciências sociais a construção de outra explicação da realidade em movimento. Nesse processo, os geógrafos questionaram as bases e o potencial explicativo da disciplina para renovar o seu conteúdo e assim a sua abordagem da problemática do presente.

No caso do Brasil, a ruptura crítica insere-se no momento da ditadura civil-militar, um período de autoritarismo e repressão política, social e intelectual. $\bigcirc$ questionamento que move esta reflexão, portanto, se deu no sentido de compreender como um pensamento crítico - a Geografia Crítica - se fortalece e prolifera em um momento de repressão.

Cabe destacar que a própria ditadura civil-militar pode ser considerada um momento de ruptura na história do Brasil. Arantes (2010) e Toledo (2004) enfatizam que esse período marca um momento de exceção verdadeiramente inédita e moderna, que no entanto se reproduz por meios jurídicos e políticos até os dias atuais (Telles; Safatle, 2010). Para Arantes (2010), o golpe de 1964 é uma presença continuada de uma ruptura irreversível, a qual quebrou um padrão evolutivo das lutas sociais no Brasil para aprofundar o padrão de acumulação capitalista. Na mesma direção, Toledo (2004) considera que entre 1961 e 1964 houve um aumento de significativa importância na luta de classes no Brasil, processo que foi brutalmente interrompido com o golpe de 1964, deflagrado contra a incipiente democracia política da época e contra as reformas sociais do governo de João Goulart. A ditadura, portanto, consolidou o "estancamento do amplo e rico debate ideológico e cultural que estava em curso no país" (Toledo, 2004, p. 15), instaurando um regime que não era favorável à construção de algo novo no Brasil, apenas contra as reformas políticas, contra a reforma agrária, contra o comunismo e contra a politização dos trabalhadores e de suas lutas. Assim, foi um período de rearranjo de classes que fundamentou uma modernização conservadora por meios autoritários, repondo as elites no poder e ampliando as desigualdades sociais.

Para este artigo, optou-se por compreender o período da ditadura civil-militar tendo como eixo condutor da discussão a própria universidade e, mais especificamente, o Departamento de Geografia da Faculdade de Filosofia da USP. Assim, apresenta-se aqui uma reflexão sobre os mandos e desmandos do regime autoritário na universidade para compreender o contexto institucional do Departamento em questão.

\section{A ditadura civil-militar como processo de modernização autoritária}

$\bigcirc$ golpe de 1964, que iniciou o período da ditadura civil-militar brasileira, foi parte de uma conspiração de alguns setores das elites nacionais e das Forças Armadas para a deposição do presidente João Goulart. Essas elites viam o governo de Goulart como uma ameaça à sua posição e ao status quo, pois o início da década de 1960 foi marcado por um avanço das lutas 
sociais e do sindicalismo, que teriam sido incentivados pela política populista do presidente à época (Ridenti, 2014). $\bigcirc$ governo de Goulart era tido como responsável por diversas pressões distributivas, concretizadas nas chamadas reformas de base (Napolitano, 2014), e a sua retirada forçada do poder, por meio de golpe instaurado no dia 1 de abril de 1964 iniciou uma intervenção saneadora contra o crescimento das esquerdas, a qual ocorreu em diversos âmbitos: na luta política, nas demandas reformistas, na produção intelectual e cultural, entre outros, processos que já foram analisados por diversos autores (Fernandes, 1984; Motta, 2014a; Ridenti, 2007, 2010, 2014; Schwarz, 2008, 2012).

Sob o nome de "revolução", os militares derrubaram o governo constitucional, com o apoio do empresariado nacional, das oligarquias rurais, da grande imprensa, de parte do clero e de alguns setores da classe média, dando início a uma sequência de 21 anos de presidências militares eleitas indiretamente. $\bigcirc$ primeiro governo militar, em nível nacional, foi do marechal Castelo Branco, que criou uma política voltada para a acumulação de capital (Oliveira, F., 2003) e reforma conservadora do Estado brasileiro, dando os primeiros passos para uma longa ditadura (Napolitano, 2014).

Os anos iniciais do regime foram marcados pelos primeiros indícios da repressão política e pela construção de uma ordem social e institucional autoritária e centralista (Napolitano, 2014). Por meio de Atos Institucionais (AI), o poder executivo federal impôs suas reformas constitucionais e ampliou legalmente as atribuições do presidente da República, tais como: decreto do Estado de Sítio, fechamento temporário do Congresso Nacional, das Assembleias Legislativas e das Câmaras de Vereadores, cassação de deputados e suspensão temporária dos direitos civis dos cidadãos (AI-2, de 1965); estabelecimento de eleições indiretas para governadores de estados, nomeação direta das prefeituras das capitais e proibição da organização em partidos políticos, os quais foram obrigatoriamente postos na clandestinidade (AI-3, de 1966); e a suspensão do direito de habeas corpus, que abriu as portas para a prática da tortura como recurso de interrogatório (AI-5, de 1968) (Starling, 2014).

Todos os setores da sociedade brasileira foram diretamente atingidos pelo regime autoritário, embora diferentemente de acordo com as classes sociais e posturas políticas. $\bigcirc$ discurso militar enfatizava a necessidade de modernização da economia, a qual se daria, certamente, sob moldes capitalistas (Motta, 2014a, 2014b; Napolitano, 2014; Oliveira, F, 2003; Ridenti, 2010, 2014): altas taxas de crescimento econômico entre 1967 e 1973 associadas à ampliação das desigualdades sociais, ${ }^{2}$ profundas transformações demográficas ${ }^{3}$ e uma grave crise que

2 Nesse período, denominado milagre econômico, as taxas de crescimento atingiram 10\% ao ano. Valendo-se de recursos como amplo endividamento externo e administração de preços, sistemas de incentivos fiscais e subsídios, o Estado passou a exercer comando quase absoluto sobre a área econômica nacional. Também a incorporação de novos trabalhadores no mercado formal de trabalho e a consolidação de um segmento médio de consumidores garantiram o êxito dessa política econômica interna, que gerou novos mercados e novos compradores, constituindo uma classe média que, pela primeira vez na história do Brasil, tinha acesso a bens de consumo e a educação (Luna; Klein, 2014a). No entanto, segundo Francisco de Oliveira (2003), tal política econômica aprofundou as desigualdades de renda: em 1960, o 1\% mais rico da população se apropriava de cerca de $11,72 \%$ da renda nacional, pouco mais do que o apropriado pelos 40\% mais pobres. Já em 1970, os 5\% mais ricos se apropriavam de uma parcela da renda ainda maior que a parcela apropriada por $60 \%$ da população: $27,35 \%$ contra $25,18 \%$.

3 A ditadura militar marca uma época de profundas mudanças estruturais da história brasileira. A ampliação do acesso à educação pública primária e secundária se reflete nos índices de alfabetização: em 1940, apenas 38,4\% da população era alfabetizada, índice que subiu levemente, para 42,7\%, em 1950, mas que atingiu 66\% em 1970 e $74 \%$ em 1980. A 
gerou um processo inflacionário desenfreado. ${ }^{4}$ De acordo com Ridenti (2010, p. 290), essas políticas constituíram uma modernização autoritária: "Os governos militares promoveram o desenvolvimento, embora à custa do cerceamento das liberdades democráticas e com grande concentração de riquezas".

Na esteira de modernizações, o ensino universitário também passou por transformações radicais. Para Motta (2014b), o papel das universidades na formação de elites administrativas, técnicas e intelectuais fez destas um dos principais alvos da modernização autoritária. Portanto, o interesse no período da ditadura civil-militar dirige-se agora a compreender especificamente essa modernização do ensino superior, seus argumentos e consequências para a USP.

\section{Modernização autoritária implementada nas universidades: repressão e luta na USP}

A Reforma Universitária, promulgada em forma de lei em novembro de 1968, marca a intenção de conectar as universidades à trilha do desenvolvimentismo autoritário, ao determinar a racionalização de recursos, a busca de eficiência, ao mudar a forma do exame vestibular, ao aumentar a participação da iniciativa privada e ao reorganizar a carreira docente.

De acordo com Luiz Antônio Cunha (1988), Giannotti (1986) e Fernandes (1975), a reforma pautou-se num modelo estadunidense de universidade: as faculdades se tornaram departamentos, as cátedras se transformaram em disciplinas e o currículo passou a ser estruturado a partir de um sistema de créditos que permitia expandir vagas ${ }^{5}$ sem aumentar proporcional e simultaneamente o número de professores de cada curso.

De acordo com Napolitano (2014), a Reforma Universitária se revestiu de um discurso modernizador da estrutura considerada arcaica do ensino superior, a qual alimentava a agitação estudantil. Para o autor, "O movimento estudantil ainda dispunha de certa margem de ação política, sobretudo dentro das universidades, tomando para si a tarefa de criticar o regime e de ser a vanguarda da luta por mudanças sociais" (Napolitano, 2014, p. 88). As transformações no ensino levadas a cabo pela Reforma Universitária, portanto, não eram apenas medidas para modernizar a estrutura universitária, mas também para, a partir dessa modernização, despolitizar as atividades acadêmicas e desafogar a pressão por mais vagas no ensino superior.

ampliação dos sistemas públicos de saúde e aposentadoria mudou radicalmente a relação entre mortalidade e fertilidade no país: entre 1940 e 1960, houve uma rápida queda na mortalidade infantil, o que gerou um acelerado aumento da população brasileira. Nas duas décadas seguintes (1970 e 1980), essa queda na mortalidade foi acompanhada por uma queda na fertilidade, tendo como consequência uma reorganização da pirâmide etária brasileira (Luna; Klein, 2014b). $\bigcirc$ período também é marcado por um intenso processo de urbanização, impulsionado pelo êxodo rural: durante a década de 1960 , cerca de 13,5 milhões de pessoas deixaram as áreas rurais e, na década seguinte, foram cerca 15,6 milhões de migrantes para as áreas urbanas. Nos anos 1980, pela primeira vez, a população rural brasileira diminuiu em números absolutos, consolidando-se em 67\% da população do país vivendo em cidades (Cunha, J., 2005; Martine; Camargo, 1984).

4 A crise do milagre econômico manifestou-se fortemente na década de 1980, principalmente devido ao aumento da dívida externa e ao choque na balança comercial brasileira ocasionado pelas duas crises mundiais do petróleo. $\bigcirc$ aumento desenfreado na inflação na década, que atingiu o índice de 200\% no ano em 1983, a diminuição do valor real dos salários dos trabalhadores devido à inflação e o endividamento foram as marcas profundas deixadas para os governos democráticos seguintes, a partir de 1985. Para Francisco de Oliveira (2003), a relação entre inflação e arrocho salarial caracteriza a política econômica da ditadura militar, pois revela a indissociabilidade entre a política repressiva e a economia de crescimento acelerado, demonstrando que a contenção da classe trabalhadora se fez principalmente pela contenção do seu salário.

5 De acordo com Motta (2014b), entre 1964 e 1979, o Brasil aumentou de 140 mil para 1,3 milhão o número de estudantes de graduação e de 23 para 400 o número de cursos de pós-graduação. 
É revelador dessa mencionada margem de ação política do movimento estudantil o fato de o grêmio da Faculdade de Filosofia, Ciências e Letras (FFCL) da USP ter sido alvo de uma busca, empreendida pelo Departamento de Ordem Política e Social (Dops), que resultou em apreensão de materiais ditos "subversivos" e prisão de nove estudantes da faculdade já em 2 de abril de 1964, ou seja, no dia seguinte ao do golpe (Giannazi, 2014). com isso, percebe-se que o regime via as universidades como um problema político e social prioritário, e, portanto, a reforma universitária serviria para erradicar a possibilidade de contestação à ditadura e atender às demandas de ascensão social de uma nova classe média que apoiara o golpe. Alterando sua estrutura interna, reorganizando currículos, cerceando a autonomia universitária, ampliando as vagas sem ampliar a infraestrutura e o quadro docente e, principalmente, associando diretamente o ensino científico a técnicas e tecnologia, a ditadura ofereceu a essa classe média a ascensão social por meio do diploma universitário, formando rapidamente profissionais com mão de obra qualificada para o mercado de trabalho em franca expansão na indústria (Chauí, 2001).

A Reforma Universitária atingiu tanto as universidades federais, submetidas mais diretamente ao governo nacional, quanto as estaduais, como a USP. Uma das consequências imediatas da reforma nessa universidade foi a fragmentação da Faculdade de Filosofia, Ciências e Letras. ${ }^{6}$ Depois de 1969 , os diversos cursos que compunham a faculdade foram divididos em 8 institutos e departamentos, desmembrando a unidade fundada em 1934. As Humanidades continuaram reunidas na nova Faculdade de Filosofia, Letras e Ciências Humanas (FFLCH), que agregava os cursos de Filosofia, Letras, Ciências Sociais, História e Geografia. Sobre essa ocasião, Petrone (1994, p. 22) nos conta que:

Por ocasião da reforma do Estatuto da USP, pouco antes de ficar definida a nova estrutura da Universidade, ao se tratar do destino do Departamento de Geografia prevaleceu entre nós a idéia de permanecer integrado na Faculdade de Filosofia em prejuízo de idéias como a de formação de um Instituto isolado ou de integração em um futuro [Instituto] de Geociências. A decisão tomada naquela ocasião foi decorrência não apenas de reflexões sobre o Departamento em si mas, também, de reflexões sobre a Faculdade, a Universidade e as particulares condições históricas que se estava vivendo. Para a grande maioria das pessoas vinculadas ao Departamento, a permanência na Faculdade de Filosofia tinha um significado muito grande e, portanto, nela o Departamento permaneceu.

De acordo com Candido (2004) e Fernandes (1984), a FFCL detinha uma postura política e ideológica "contra a corrente": como instituição, seu corpo docente, seus alunos e principalmente as pesquisas conduzidas na faculdade demonstravam um compromisso social com as camadas mais pauperizadas da população e que constituiu-se ao longo dos anos numa tradição de pensamento crítico sobre a sociedade brasileira.

De acordo com Candido (1992), predominou na FFCL da USP o interesse por estudos concretos das realidades fundamentais da sociedade brasileira em temas como habitat, moradia, zonas pioneiras, crenças e práticas populares, entre outros. Esse teria sido o início de uma tradi-

6 A Faculdade de Filosofia, Ciências e Letras (FFCL) da Universidade de São Paulo foi criada em 1934, no momento de fundação da própria universidade. 
ção de pensamento sobre o homem comum e sua condição no Brasil. Portanto, a FFCL iniciou uma nova era, em São Paulo, ao deslocar o objeto dos estudos da sociedade das camadas dominantes para as camadas oprimidas, optando pela investigação de grupos marginalizados. Entre as pesquisas que caminharam nessa direção, Candido (1992) cita, na Sociologia, o trabalho de Florestan Fernandes sobre a situação do negro; na Antropologia, o trabalho de Emílio Willems sobre o caipira, o trabalho de Gioconda Mussolini sobre os pescadores e o trabalho de Egon Schaden sobre grupos indígenas; e na Geografia o trabalho de Nice Lecocq Müller sobre sitiantes.

De acordo com Chauí (2003), Candido (2004), Chnaiderman (2004), Garbuglio (2004) e Emilia Viotti da Costa (2004), o momento mais marcante da história da FFCL e representativo do combate ideológico ao regime militar característico dessa instituição foi o confronto entre estudantes da FFCL e da Universidade Mackenzie, em outubro de 1968 na rua Maria Antônia.

Três departamentos da FFCL (Ciências Sociais, Filosofia e Letras) e a biblioteca funcionavam, desde o início dos anos 1940, num edifício à rua Maria Antônia, próximo ao centro da cidade de São Paulo. ${ }^{7}$ Na mesma rua, no edifício em frente, funcionava a Universidade Mackenzie (UM), instituição de ensino particular que era conhecida por seus alunos e professores favoráveis à ditadura e antiesquerda.

Segundo Mathias et al. (1988), no dia 2 de outubro de 1968 um grupo de estudantes secundaristas fazia uma campanha de recolhimento de fundos para a realização do congresso da União Nacional dos Estudantes (UNE), na rua das duas faculdades em questão. Um grupo de alunos da Universidade Mackenzie contrários àquela campanha começou a atirar pedras e pedaços de pau nos estudantes secundaristas na rua, que, acudidos pelos alunos da FFCL, responderam atirando igualmente pedras nos adversários. $\mathrm{O}$ conflitou durou cerca de duas horas naquele dia, mas foi retomado no seguinte, 3 de outubro, pelos alunos da UM.

Além de paus e pedras, os estudantes da faculdade particular começaram a atacar o prédio da FFCL com bombas, objetos incendiários, panos molhados com ácido e tiros de armas de fogo. Segundo diversos relatos, os alunos da FFCL não estavam armados como os da UM. Esses ataques foram atribuídos ao grupo denominado Comando de Caça aos Comunistas (CCC), ${ }^{8}$ do qual alguns membros eram alunos da UM.

Depois de algumas horas de conflito, o saldo era de um aluno morto por tiros, 4 alunos feridos a bala e inúmeros alunos e professores feridos por pedras e queimados por ácido. Todos os feridos faziam parte do corpo da faculdade da USP, e não da UM, o que revela a desigualdade de instrumentos de luta entre os grupos.

7 O curso de Geografia já havia sido transferido, em 1966, para o campus do bairro do Butantã (Mathias et al., 1988).

8 O Comando de Caça aos Comunistas (CCC) foi uma organização paramilitar anticomunista de extrema direita que atuou primordialmente nos anos 1960. Esse grupo foi responsável por um conjunto de ações como sequestros e assassinatos de militantes das organizações de esquerda, atentados explosivos, invasões e espancamento de grupos artísticos críticos da ditadura. A organização era composta majoritariamente por estudantes universitários (sobretudo da Universidade Mackenzie, da Faculdade de Direito do Largo São Francisco da USP e da Pontifícia Universidade Católica, PUC-SP). Também pertenciam ao CCC policiais, membros de organizações da direita católica como a Opus Dei e a TFP (Tradição, Familia e Propriedade) e intelectuais favoráveis ao regime militar. Ressalta-se que, desde 1964, estudantes do Mackenzie ligados ao CCC tinham escolhido como alvo de algumas de suas ações a Faculdade de Filosofia da USP, e suas práticas consistiam em invadir, destruir, perseguir e aterrorizar os alunos. Em 1964, 1966 e 1967 , invadiram a Faculdade de Filosofia destruindo móveis e vidraças e espancando estudantes. Sua ação em 1968, durante a batalha da Maria Antonia, foi mais um dos atos violentos cometidos pela organização, num conjunto de outros graves atentados (Antunes; Ridenti, 2007; Motta, 2010). 
Durante o confronto, um grupo de professores e alunos - entre eles, Eurípedes Simões de Paula, no momento diretor da FFCL, Antonio Candido, José Arthur Giannotti e Pasquale Petrone - saiu da faculdade rumo à Secretaria Estadual de Segurança, buscando autoridades para que dessem um fim ao conflito, que já contava um morto e diversos feridos. A atuação da polícia na ocasião foi uma evidência de sua parcialidade dessa e da atitude repressiva à esquerda universitária: após chegar ao local, "A polícia observava, impassível, a depredação de uma propriedade do Estado [o edifício da FFCL], a utilização de armas de fogo, a entrada de material de luta na Universidade Mackenzie, como pedras, caixas de fogos e galões de gasolina, sem fazer um gesto para evitar todos esses fatos" (Mathias et al., 1988, p. 19).

Quando a polícia começou a agir, no entanto, foi apenas contra os alunos e professores da USP, invadindo o prédio da FFCL e o da Faculdade de Ciências Econômicas, que ficava nas proximidades. Nessa operação, diversas pessoas foram presas e levadas para prestar depoimento aos agentes da repressão, a maioria alunos da FFCL mas também três professores (Paula Beiguelman, Maria do Carmo C. de Souza e Bento Prado Jr). Nenhum aluno da UM foi detido na ocasião.

Em entrevista, a professora Odette Carvalho de Lima Seabra relatou que estava presente nesse dia da chamada batalha da Maria Antônia, e que inclusive integrou a comissão de professores e alunos que se dirigiu à Secretaria Estadual de Segurança para solicitar a intervenção do poder público no sentido de encerrar o conflito. A professora relembrou que o prédio da FFCL pegava fogo, inclusive a biblioteca, e que a intenção dos alunos da UM era justamente destruir o edifício da USP. Nesse momento, o conflito contava já com um aluno morto, diversos feridos, carros virados na rua e o prédio em chamas. Após a intervenção da polícia, diversos alunos que estavam na Maria Antônia foram à Cidade Universitária e realizaram uma assembleia estudantil no salão do Crusp, a qual foi, também, invadida pela polícia. Os alunos fugiram, inclusive a professora Odette C. de Lima Seabra que relata ter corrido pelo matagal do campus até o Jaguaré.

Também em 1968, em 17 de dezembro - apenas quatro dias depois da promulgação do Al-5 - outro ataque à universidade foi empreendido, desta vez diretamente pelos agentes da ditadura. O Conjunto Residencial da Universidade de São Paulo (Crusp), residência universitária voltada para o auxílio dos alunos mais pobres da USP, foi invadido pelas forças militares, que entraram nos prédios e casas dos alunos realizando buscas por "material subversivo" e seus detentores. Nessa invasão, diversos estudantes foram presos - entre eles, o agora professor Ariovaldo Umbelino de Oliveira - e os prédios da residência universitária ficaram interditados até 1979, quando foram retomados por iniciativa dos alunos (Adusp, 2009).

O Crusp, conforme relatou em entrevista a professora Odette C. de Lima Seabra, mesmo quando não havia mais o direito de manifestação e o movimento estudantil estava já enfraquecido, continuava sendo um lugar de reuniões políticas e debate. Nas suas palavras, "se fazia política no Crusp". O CCC, que coordenou o ataque à Maria Antônia, empreendeu diversas ações no Crusp, a maioria com armas de fogo para atirar contra os prédios (Benedito, 2008). Assim, percebe-se que esse foi um ponto fulcral na organização dos estudantes da USP durante a ditadura, e por isso mesmo diversas vezes atingido.

Outra manifestação da interferência da ditadura na universidade foi a criação das chamadas Comissões de Inquérito, cujo objetivo era identificar e punir responsáveis por infiltrar ideias marxistas e agentes de subversão nas universidades, tanto estudantes quanto profes- 
sores. Funcionando como uma assessoria de informação da Reitoria, essa comissão recolhia informações a partir de panfletos, boletins, murais estudantis, relatos de congressos, de aulas e semanas de estudo. Segundo Elias (1998, p. 15):

Os órgãos de informação registram rigorosa vigilância sobre o campus da Cidade Universitária, em São Paulo, gerando três relatórios diários - pela manhã, tarde e noite -, durante anos, sobre o que ocorre de mais significativo em cada uma das faculdades. Há observações [...] de aulas, palestras, conferências, assembléias estudantis, quase que caracterizando uma rotina que nunca se altera.

Uma das formas de punir intelectuais considerados "subversivos" foi expurgá-los por meio de aposentadoria compulsória ou demissão, o que constituiu um modo de afastá-los obrigatoriamente de suas atividades de ensino e pesquisa, retirando-os da universidade. Após o Al-5, entre dezembro de 1968 e abril de 1969, emitiram-se dois decretos, expurgando no total 27 professores da USP. No caso da FFCL, foram compulsoriamente aposentados os professores: Florestan Fernandes, Octavio lanni e Paul Israel Singer, do Departamento de Sociologia; Bento Prado Jr. e José Arthur Giannotti, do Departamento de Filosofia; Fernando Henrique Cardoso e Paula Beiguelmen, do Departamento de Ciência Política; Emília Viotti da Costa, do Departamento de História; Ada Natal Rodrigues, do Departamento de Linguística; e Mário Schenberg e Jaime Tiomno, do Departamento de Física (Adusp, 1979; Giannazi, 2014). Em ambos os decretos consta, entre os punidos, o nome de Caio Prado Jr., que nunca ocupou nenhum cargo na Universidade de São Paulo. Ele tinha apenas a formação, como aluno, em Direito e em Geografia e História, e o título de livre-docente pela Faculdade de Direito. Para Giannazi (2014), o fato de Caio Prado Jr. constar entre os expurgados revela não só uma certa falta de cuidado daqueles que elaboraram e escolheram os punidos, mas também a intenção de impedir que esse intelectual viesse a ser professor da USP, caso fosse aprovado em algum concurso da universidade.

As expulsões, no entanto, não eram resultado apenas das supostas atividades subversivas e políticas de tais professores:

$\bigcirc$ fato de estarem, na grande maioria dos casos, as vítimas das duas listas entre os elementos mais destacados de suas especialidades, alguns deles com renome internacional e outros despontando como cientistas dos mais promissores, explica, em grande parte, as perseguições que sofreram. As aposentadorias, portanto, os removiam do caminho de elementos medíocres, que lhes temiam a concorrência, ou de outros que, por afoiteza, não desejavam investir seu tempo nos trabaIhos de qualificação que thes dariam o grau de excelência que invejavam nos rivais intelectualmente mais qualificados (Giannazi, 2014, p. 55).

Dessa forma, vê-se que tais punições serviram também para, em certa medida, rearranjar a perspectiva de ingresso e progressão na carreira do quadro docente da universidade, abrindo caminho para a ascensão de professores mais alinhados com a modernização autoritária em curso. 
Nenhum professor do Departamento de Geografia foi expurgado da universidade. No entanto, a professora Maria Regina Cunha de Toledo Sader relata em memorial apresentado para concurso em 1988 que, após a defesa da sua dissertação de mestrado, em 1970, foi para a França estudar com uma bolsa do governo francês em situação de exilio:

Minha casa havia sido invadida por elementos do exército, após uma breve detenção minha e de meu marido [o sociólogo Eder Sader] pelo aparato civil de repressão. Perdemos muitas coisas, entre elas, todo meu material de pesquisa, minhas entrevistas, questionários, levantamentos estatísticos e cartas, junto com artigos escritos e não publicados e toda a nossa biblioteca (Sader, 1988, p. 4).

A professora Maria Regina Sader retornou ao Brasil em 1971, mas em 1972 exilou-se mais uma vez, nesse momento no Chile, país onde também foi perseguida depois do golpe de 1973. Nessa ocasião, partiu para a França e lá permaneceu até a anistia em 1979 (Sader, 1988). Em 1980, Maria Regina Sader prestou novo concurso para ser professora no Departamento de Geografia da USP. Segundo relato da professora Odette C. de Lima Seabra, esse novo concurso foi necessário, pois, quando do exílio da professora Maria Regina Sader no início na década de 1970, a Congregação da FFLCH teria declarado abandono de cargo por parte da professora, o que no serviço público caracteriza motivo para a sua exoneração?. Assim, quando retornou, foi necessária a aprovação em um novo concurso para que pudesse retomar as suas atividades docentes na USP.

Para a comissão da Adusp, responsável pela publicação do texto O livro negro da USP - o controle ideológico na universidade, ${ }^{10}$ esse controle foi o fundamento para a criação de um mecanismo interno de "caça às bruxas":

Em primeiro lugar é necessário apontar que a repressão policial que se dirige contra a Universidade imediatamente após trinta e um de março não encontrou nenhuma resistência por parte da Reitoria, mas se fez com sua conivência. A forma violenta pela qual foram realizadas prisões de professores e alunos, a invasão e a depredação da Faculdade de Filosofia, configuram claramente a intenção de intimidar antes que investigar e não sofreram o mais leve reparo por parte do Reitor. Deste modo, a ação repressiva externa pode agir livremente na Universidade e criar uma atmosfera de temor generalizado provocada pelos atos de violência e pela ameaça permanente de prisões e de detenções arbitrárias (Adusp, 1979, p. 11).

9 Infelizmente, não foi possível confirmar essa informação antes da conclusão da pesquisa. No entanto, consideramos que essa investigação seria importante devido à proximidade com o caso da professora Ana Rosa Kucinski, docente do Instituto de Química da USP que foi demitida em 1975 por abandono de cargo. No entanto, a professora, militante da Aliança Libertadora Nacional (ALN), estava desaparecida desde abril de 1974, quando fora presa por agentes da polícia de São Paulo. Em abril de 2014, a Congregação do Instituto de Química votou e aprovou a anulação da demissão da docente a pedido da Comissão da Verdade da USP. Também emitiu um pedido oficial de desculpas à família de Ana Rosa Kucinski, declarando que sua demissão, à época, foi um equívoco (Brasil, 2014).

10 Publicado pela primeira vez em 1978, ainda durante a ditadura, o livro traz um compêndio de denúncias sobre a atuação da repressão na universidade, através dos seus mecanismos internos e externos de informação. É importante destacar que o livro foi republicado em 2004 com novo título, O controle ideológico na USP (1964-1978): "Mudamos o título original, nesta nova edição, para não incorrer na conotação certamente involuntária de discriminação racial, atentos aos alertas do movimento negro quanto à recorrente associação do adjetivo 'negro' a algo negativo" (Adusp, 2004, p. 6). 
Sobre a conivência da Reitoria da USP com os atos de repressão e autoritarismo na universidade, cabe destacar que dois reitores foram nomeados ministros da Justiça durante a ditadura: o jurista Luís Antônio da Gama e Silva, professor da Faculdade de Direito, quando foi licenciado como reitor da USP para assumir o posto de ministro no governo do general Costa e Silva, e o também jurista Alfredo Buzaid, professor na mesma Faculdade e também reitor, assumiu o Ministério da Justiça durante o governo Médici. Gama e Silva, inclusive, elaborou o texto do Al-5, promulgado em dezembro de 1968, e assinou, juntamente com o general-presidente, os decretos de expurgos dos professores da USP em abril de 1969 (Giannazi, 2014).

Além das aposentadorias e demissões, a publicação da Adusp expõe também a existência de um mecanismo de triagem ideológica nas contratações de novos professores e funcionários. "Após as aposentadorias por força do AI-5, começam a ocorrer na USP fatos até então desconhecidos: contratos aprovados nos Departamentos e Congregações, com demonstração de verbas, são misteriosamente arquivados na Reitoria ou indeferidos pelo Reitor sem explicação" (Adusp, 1979, p. 55). Tratava-se de mais uma comissão especial, externa à USP, que fornecia à administração universitária informações sobre os concursados a partir dos dados dos órgãos nacionais de segurança. Denominadas cassações brancas, diversas denúncias de arquivamento de processos de contratação foram encaminhadas à Adusp entre 1975 e 1978. Uma delas, que nos interessa especialmente, é assinada por cinco candidatos aprovados em seus departamentos e congregações, dois deles pelo Departamento de Geografia: Odette Carvalho de Lima Seabra e Maria Niedja Leite de Oliveira." Ambos os processos foram arquivados na Reitoria em 1976, sem explicação ou justificativa.

No processo de contratação da professora Odette Carvalho de Lima Seabra, atualmente arquivado no Setor de Expediente da FFLCH, constam os documentos correspondentes, com datas entre 1975 - ano da sua aprovação por concurso - e 1981 - ano da sua contratação efetiva. Verifica-se nesses documentos uma série de pedidos e atualizações de demonstração de verbas do Departamento de Geografia comprovando a necessidade e possibilidade de contratação da candidata aprovada em concurso, assim como o constante arquivamento desses documentos por parte da reitoria. Tais documentos, na perspectiva aqui defendida, demonstram uma demora intencional na contratação da professora. Não consta nesse processo, evidentemente, nenhuma assinatura, parecer ou avaliação externa à USP, como das Comissões de Inquérito que prestavam serviços à Reitoria. $\bigcirc$ único motivo alegado para a não contratação foi a falta de recursos financeiros, argumento diversas vezes respondido tanto pelo Chefe de Departamento, Pasquale Petrone, quanto pelos diretores da FFLCH. Considera-se, portanto, que, não havendo razão técnica ou institucional para a não contratação da professora Odette C. de Lima Seabra, visto que diversos demonstrativos financeiros foram encaminhados

11 Conforme consta em relato sobre a 55a Caravana da Anistia, realizada em 2012, Maria Niedja Leite de Oliveira foi confundida com sua irmã, Maria Nadja Leite de Oliveira. A primeira foi aprovada em concurso para Auxiliar de Ensino no Departamento de Geografia da USP em 1976, mas foi impedida de ocupar o cargo devido à triagem ideológica que a confundiu com Maria Nadja, militante em Fortaleza de um grupo contra a ditadura. Ambas foram presas e torturadas no Dops, em São Paulo. Em 2012, Maria Niedja Leite de Oliveira recebeu uma indenização retroativa, referente ao período de nove anos em que ficou à espera da sua contratação na USP (Brasil [...], 2012). 
e unanimemente aprovados no Conselho do Departamento de Geografia, o motivo do atraso foi político e tem relação com a história pessoal da professora, que participou ativamente do movimento estudantil e foi militante da Polop ${ }^{12}$ (Verdi, 2016).

Portanto, a fragmentação da FFCL, os expurgos, as cassações brancas, as investigações empreendidas pelas comissões de inquérito, fazem parte de um processo de castração da universidade, de sufocamento do pensamento crítico (Fernandes, 1984), afastando dela a produção acadêmica - ensino e pesquisa - que refletia sobre a ordem social vigente, estudando-a e militando pela sua transformação.

Em resumo, considera-se aqui que a Faculdade de Filosofia da USP encampou a luta contra a ditadura pautando tanto questões teóricas, em grupos de estudo, revistas e aulas, quanto questões práticas, ao enfrentar os opositores e a própria polícia, que via a universidade como um centro de subversão ao regime. Nas palavras de João de Moraes (1988, p. 112-113):

À Faculdade de Filosofia coube assim o arriscado privilégio de encarnar o espírito de crítica e de contestação que culminou na grande agitação de 1968. [...] Situando-a em uma perspectiva histórica mais ampla, a ativa resistência que a Maria Antônia opôs àqueles que finalmente viriam destruí-la se inscreve na luta secular por uma democracia social e cultural e particularmente por uma universidade crítica e atuante que representa ainda hoje a melhor esperança de um país onde a lei é feita para os milionários e a cidadania para todos permanece um direito a conquistar. Sim, houve ingenuidade e até inconseqüência na euforia revolucionária de 68. Mas o que sobretudo permaneceu foi a crispação da vontade de dizer "não" à miséria das circunstâncias.

Para Fernandes (1984), a ditadura militar não podia tolerar que uma instituição chave para a formação de quadros intelectuais da elite brasileira se constituísse como uma resistência não apenas defensiva, mas que ousava desafiar o poder arbitrário do regime e ameaçá-lo com a democracia, ou com uma revolução democrática. É nesse sentido que compreende-se aqui a consolidação de todo um aparato repressivo e ações opressoras para a eliminação desse caráter crítico e radical que existiu na Universidade de São Paulo durante a ditadura civil-militar.

No caso específico do Departamento de Geografia, percebe-se que grande parte da resistência à ditadura vinha do movimento estudantil, e não da instituição. Os militantes contra o regime, que inclusive foram presos, eram os alunos e não os professores (Benedito, 2008). Em 1968, o professor Ariovaldo Umbelino de Oliveira, na época estudante de Geografia, era presidente do Centro Acadêmico. $\bigcirc$ primeiro presidente do DCE da USP, fundado em 1976, Geraldo Siqueira, era aluno do Departamento, conforme conta Antonio Carlos Robert Mora-

12 A Organização Revolucionária Marxista Política Operária (Polop) foi um grupo clandestino entre os diversos da esquerda brasileira que lutaram contra a ditadura (Ridenti, 2014). Fundada em 1959, a organização é considerada por Reis Filho (2007) uma matriz da esquerda revolucionária brasileira. Uma das pautas da organização era a união das lutas do movimento estudantil e do movimento operário, e contava com o sociólogo Eder Sader - marido da professora Maria Regina Cunha de Toledo Sader - entre os seus militantes (Coelho; Santos, 2011). Em seu relato, a professora Odette C. de Lima Seabra conta que foi militante desse grupo justamente porque ele se propunha a integrar-se ao movimento operário. Foi por meio da militância que ela teve acesso à uma bibliografia proibida pela ditadura, que era usada para dar cursos aos operários. Para a professora, sua história de militância tem relação com uma "herança sanguínea", pois na infância e adolescência conviveu com tios operários que militavam na fábrica Santa Marina, em São Paulo. 
es (in Scarim (2000); o próprio Moraes, Wanderley Messias da Costa e André Martin, todos estudantes do curso de Geografia, eram filiados ao PCB e formavam um núcleo do partido na USP (Pedrosa, 2015).

A FFLCH foi um dos berços do renascimento do movimento estudantil na ditadura (Moraes, A., 2004) e é justamente esse movimento estudantil que vai radicalizar também a própria ciência geográfica com outro entendimento da realidade. $\bigcirc$ momento de eclosão desse movimento teria sido o já mencionado Encontro Nacional de Geógrafos de 1978, ocasião em que se consolida um grupo de pessoas com atuação militante e interesse em criar uma Geografia diferente, politizada e de esquerda, nas palavras de Antonio Moraes (in Scarim, 2000).

O desejo de transformação de uma sociedade política e intelectualmente oprimida por um regime que transformava os rumos do Brasil e da ciência, alterando profundamente os centros da reflexão sobre o próprio país, associado à busca por novas abordagens teóricas e metodológicas que fossem capazes de superar a chamada crise da Geografia, consolidaram uma nova compreensão das relações entre sociedade e espaço (Verdi, 2016). Isso, no entanto, foi construído a partir de um longo processo, que se inicia com uma insatisfação frente à Geografia, a identificação de uma crise da disciplina, fruto da sua incapacidade de desvendamento de uma realidade que estava passando por uma série de transformações, tornando obsoletos diversos conceitos e construções da ciência geográfica. Nessa trajetória, diversos geógrafos em formação escolheram a abordagem marxista, o materialismo histórico e a compreensão dialética da realidade, assim elaborando novos conteúdos para os conceitos, categorias e objeto da Geografia, denominando crítica essa nova elaboração, para diferenciá-la da anterior, dita tradicional; tudo que os jovens geógrafos e militantes, insatisfeitos, não queriam ser: tradicionais.

De acordo com Antonio Moraes (2005), a Geografia tradicional, de cunho positivista, realiza uma naturalização dos fenômenos humanos por compreender a ciência geográfica como aquela do contato entre o domínio da natureza e o domínio da humanidade. O ser humano é visto como um dos diversos elementos da paisagem, como um dado do lugar. Essa concepção estabelece os termos da relação entre os indivíduos - não a sociedade - e a natureza - não o espaço - criando uma ciência natural dos fenômenos humanos. Ainda para Antonio Moraes (2005, p. 41), "Tal perspectiva naturalista aparece com clareza no fato de buscar esta disciplina a compreensão do relacionamento entre o homem e a natureza, sem se preocupar com a relação entre os homens". O materialismo histórico permite inverter essa relação e, com isso, compreender que o espaço é um produto social.

Essa compreensão do espaço como produção social, essencialmente dialética, atribui conteúdos sociais ao próprio espaço. Entre eles, as classes sociais. $\bigcirc$ espaço que, sob o modo de produção capitalista, é produzido por uma sociedade dividida em classes, é produto também da luta de classes. Quando se compreende que a luta de classes é o motor da história, como fizeram Ariovaldo de Oliveira (1978), Carlos (1979), Wanderley da Costa (1982), João de Moraes (1983), Damiani (1984), Vesentini (1984), Lencioni (1985), Seabra (1979, 1987) entre outros, essa adquire uma nova importância na análise das determinações da produção social do espaço. Muda, portanto, o conteúdo da relação entre espaço e tempo, entre Geografia e História: trata-se de um espaço socialmente produzido por uma sociedade dividia em classes, cujo movimento é dado por suas próprias contradições, que se realizam espacialmente. 
Tal movimento é fruto do entendimento de que o trabalho é a mediação necessária entre a sociedade e a natureza. É o trabalho que transforma simultaneamente e dialeticamente tanto um quanto outro. Considera-se, portanto, que é essa mediação a responsável por redirecionar as reflexões e questões de pesquisa na Geografia brasileira, fundamentando assim a ruptura crítica (Verdi, 2016).

\section{Considerações finais}

Para concluir, cabe retomar Candido (1990, p. 4): "o radicalismo forma contrapeso porque é um modo progressista de reagir ao estímulo dos problemas sociais prementes". Nessa perspectiva, defende-se aqui que a Geografia Crítica constituiu contrapeso dessa natureza ao reelaborar epistemologicamente a ciência geográfica brasileira frente à necessidade de produzir uma explicação da realidade social, econômica e política do país. Ainda para Candido (1990), o pensamento radical seria um agente do possível. $\bigcirc$ desafio é estar continuamente refletindo sobre nosso fazer geográfico, sempre tendo o radicalismo como horizonte do possível/impossível, sem abrir mão do nosso papel crítico e da práxis frente ao futuro sombrio que se desenha.

\section{Referências}

ADUSP. ASSOCIAÇÃO DOS DOCENTES DA USP. Ditadura e Resistência. Revista Adusp, out. 2009.

ADUSP. ASSOCIAÇÃO DOS DOCENTES DA USP. O controle ideológico na USP (1964-1978). São Paulo: Adusp, 2004.

ADUSP. ASSOCIAÇÃO DOS DOCENTES DA USP. O livro negro da USP: o controle ideológico na Universidade. São Paulo: Brasiliense, 1979.

ANTUNES, R.; RIDENTI, M. Operários e estudantes contra a ditadura: 1968 no Brasil. Mediações, v. 12, n. 2, p. 78-89, jul./dez. 2007.

ARANTES, P. 1964, o ano que não terminou. In: TELLES, E.; SAFATLE, V. (Org.). O que resta da ditadura: a exceção brasileira. São Paulo: Boitempo, 2010. p. 205-236.

BENEDITO, M. 1968, por aí... memórias burlescas da ditadura. São Paulo: Publisher Brasil, 2008.

BRASIL. Comissão Nacional da Verdade. Relatório. Brasília: CNV, 2014.

BRASIL anistia e homenageia mulheres combatentes pela democracia. Portal Vermelho, 11 mar. 2012. Disponível em: http://www.vermelho.org.br/noticia/177759-1. Acesso em: 8 nov. 2018.

CANDIDO, A. Faculdade de Filosofia completa 70 anos. Informe FFLCH, n. 8, fev. 2004.

CANDIDO, A. A Faculdade no centenário da abolição. Revista Novos Estudos Cebrap, n. 34, nov. 1992.

CANDIDO, A. Radicalismos. Estudos Avançados, São Paulo, v. 4, n. 8, p. 4-18, jan./abr. 1990. 
CARLOS, A. F. A. Reflexões sobre o espaço geográfico. Dissertação (Mestrado em Geografia Humana) - Faculdade de Filosofia, Letras e Ciências Humanas, Universidade de São Paulo, São Paulo, 1979.

CHAUÍ, M. Marilena Chauí homenageada pela FFLCH. Informe FFLCH, n. 5, set./out. 2003.

CHAUÍ, M. S. Escritos sobre a universidade. São Paulo: Ed. Unesp, 2001.

CHNAIDERMAN, B. Entrevista com Boris Chnaiderman. Informe FFLCH, n. 8, fev. 2004.

COELHO, E.; SANTOS, I. G. Para a história da Polop (1961-1983): debate historiográfico e apontamentos iniciais de pesquisa. In: Simpósio Nacional de História - Anpuh, 26., 2011, São Paulo. Anais... São Paulo, 2011.

COSTA, E. V. Entrevista com Emilia Viotti da Costa. Informe FFLCH, n. 4, mar. 2004.

COSTA, W. M. O processo contemporâneo de industrialização: um estudo sobre a expansão da produção industrial em território paulista. Dissertação (Mestrado em Geografia Humana) - Faculdade de Filosofia, Letras e Ciências Humanas, Universidade de São Paulo, São Paulo, 1982.

CUNHA, J. M. P. Migração e urbanização no Brasil: alguns desafios metodológicos para análise. São Paulo em Perspectiva, v. 19, n. 4, p. 3-20, 2005.

CUNHA, L. A. A universidade reformanda - o golpe de 1964 e a modernização do ensino superior. Rio de Janeiro: Francisco Alves, 1988.

DAMIANI, A. L. Na busca das favelas o encontro do "peão" que permanece: as favelas de Cubatão num quadro de desenvolvimento do centro petroquímico siderúrgico. Dissertação (Mestrado em Geografia Humana) - Faculdade de Filosofia, Letras e Ciências Humanas, Universidade de São Paulo, São Paulo, 1984.

ELIAS, B. A USP nos arquivos do Dops. Revista Adusp, abr. 1998.

FERNANDES, F. A questão da USP. São Paulo: Brasiliense, 1984.

FERNANDES, F. Universidade brasileira: reforma ou revolução? São Paulo: Alfa-Omega, 1975.

GARBUGLIO, J. C. Seção de entrevistas com professores. Informe FFLCH, n. 8, fev 2004.

GIANNAZI, C. Marcha contra o saber: o golpe militar de 1964 e o AI-5 na Universidade de São Paulo. São Paulo: Global, 2014.

GIANNOTTI, J. A. A Universidade em ritmo de barbárie. São Paulo: Brasiliense, 1986.

LENCIONI, S. Agricultura e urbanização: a capitalização no campo e a transformação da cidade. Jardinópolis, o estudo de um lugar. Dissertação (Mestrado em Geografia Humana) - Faculdade de Filosofia, Letras e Ciências Humanas, Universidade de São Paulo, São Paulo, 1985. 
LUNA, F. V.; KLEIN, H. S. Transformações econômicas no período militar (1964-1985). In: REIS FILHO, D. A.; RIDENTI, M.; MOTTA, R. P. S. (Org.). A ditadura que mudou o Brasil: 50 anos do golpe de 1964. Rio de Janeiro: Zahar, 2014a. p. 92-111

LUNA, F. V.; KLEIN, H. S. Mudanças sociais no período militar (1964-1985). In: REIS FILHO, D. A.; RIDENTI, M.; MOTTA, R. P. S. (Org.). A ditadura que mudou o Brasil: 50 anos do golpe de 1964. Rio de Janeiro: Zahar, 2014b. p. 66-91.

MACHADO, L. O. História do pensamento geográfico no Brasil: elementos para a construção de um programa de pesquisa (uma conversa com Lia Osório Machado). Rio de Janeiro: Revista Terra Brasilis, ano 1, n. 1, jan./jun. 2000.

MAMIGONIAN, A. A AGB e a produção geográfica brasileira: avanços e recuos. Revista Terra Livre, São Paulo, n. 8, 1991.

MARTINE, G.; CAMARGO, L. Crescimento e distribuição da população brasileira: tendências recentes. Revista Brasileira de Estudos de População, São Paulo, v. 1, n. 1, p. 99-143, 1984.

MATHIAS, S.; CANDIDO, A.; DANTAS, C. A. B.; LYRA, C. B.; DURHAN, E. R.; CARDOSO, R. C. L. Os acontecimentos da rua Maria Antônia: 2 e 3 de outubro de 1968. São Paulo: FFLCH-USP, 1988.

MORAES, A. C. R. Geografia: pequena história crítica. 19a ed. São Paulo: Annablume, 2005.

MORAES, A. C. R. Memorial para concurso de Professor Titular. 2004. MORAES, A. C. R. Contribuição para uma história crítica do pensamento geográfico: Alexandre Von Humboldt, Karl Ritter e Friedrich Ratzel. Dissertação (Mestrado em Geografia Humana) - Faculdade de Filosofia, Letras e Ciências Humanas, Universidade de São Paulo, São Paulo, 1983.

MORAES, J. Q. Na Maria Antônia dos anos 60: a reforma da filosofia e a revanche dos golpistas. In: SANTOS, M. C. L. (Org.). Maria Antônia: uma rua na contramão. São Paulo: Nobel, 1988. p. 106-113.

MOTTA, R. P. S. A modernização autoritário-conservadora nas universidades e a influência da cultura política. In: REIS FILHO, D. A.; RIDENTI, M.; MOTTA, R. P. S. (Org.). A ditadura que mudou o Brasil: 50 anos do golpe de 1964. Rio de Janeiro: Zahar, 2014a. p. 48-65.

MOTTA, R. P. S. As universidades e o regime militar: cultura política brasileira e modernização autoritária. Rio de Janeiro: Zahar, 2014b.

MOTTA, R. P. S. Comunismo e anticomunismo sob o olhar da polícia política. Locus - Revista de História, Juiz de Fora, v. 30, n. 1, p. 17-27, 2010.

NAPOLITANO, M. 1964: história do regime militar brasileiro. São Paulo: Contexto, 2014.

OLIVEIRA, A. U. Contribuição para o estudo da geografia agrária: crítica ao "Estado Isolado" de Von Thünen. Tese (Doutorado em Geografia Humana) - Faculdade 
de Filosofia, Letras e Ciências Humanas, Universidade de São Paulo, São Paulo, 1978.

OLIVEIRA, F. A expansão pós-1964: nova revolução econômica burguesa ou progressão das contradições? In: OLIVEIRA, F. Crítica à razão dualista: o ornitorrinco. São Paulo: Boitempo, 2003. p. 93-106.

PEDROSA, B. V. A controvérsia da geografia crítica no Brasil (Partes I e II). Geosul, Florianópolis, v. 30, n. 59, p. 7-27/29-46, jan./jun. 2015.

PEET, R. O desenvolvimento da geografia radical nos Estados Unidos. In: CHRISTOFOLETTI, A. (Org.). Perspectivas da geografia. São Paulo: Difel, 1982. p. 225-254.

PETRONE, P. História do pensamento geográfico. Borrador, São Paulo, n. 2, 1994.

PROCESSO 75.1.36632.1.2: referente à contratação da prof. Odette Carvalho de Lima Seabra (1975).

REIS FILHO, D. A. Classe operária, partido de quadros e revolução socialista: o itinerário da Política Operária - Polop (1961-1986). In: FERREIRA, J.; REIS FILHO, D. A. Revolução e democracia (1964...). Rio de Janeiro: Civilização Brasileira, 2007. p. 53-71.

RIDENTI, M. As oposições à ditadura: resistência e integração. In: REIS FILHO, D. A.; RIDENTI, M.; MOTTA, R. P. S. (Org.). A ditadura que mudou o Brasil: 50 anos do golpe de 1964. Rio de Janeiro: Zahar, 2014. p. 30-47.

RIDENTI, M. O fantasma da revolução brasileira. São Paulo: Ed. Unesp, 2010.

RIDENTI, M. Esquerdas revolucionárias armadas nos anos 1960-1970. In: FERREIRA, J.; REIS FILHO, D. A. Revolução e Democracia (1964...). Rio de Janeiro: Civilização Brasileira, 2007. p. 21-51.

SADER, M. R. C. T. Memorial para concurso de Professor Assistente. 1988.

SCARIM, P. C. Coetâneos da crítica: uma contribuição ao estudo do movimento de renovação da geografia brasileira. Dissertação (Mestrado em Geografia Humana) - Faculdade de Filosofia, Letras e Ciências Humanas, Universidade de São Paulo, São Paulo, 2000.

SCHWARZ, R. Martinha versus Lucrécia. São Paulo: Companhia das Letras, 2012.

SCHWARZ, R. O pai de família e outros estudos. São Paulo: Companhia das Letras, 2008.

SEABRA, O. C. L. Os meandros do rio nos meandros do poder: o processo de valorização dos rios e das várzeas do Tietê e do Pinheiros na cidade de São Paulo. Tese (Doutorado em Geografia Humana) - Faculdade de Filosofia, Letras e Ciências Humanas, Universidade de São Paulo, São Paulo, 1987.

SEABRA, O. C. L. A muralha que cerca o mar: uma modalidade de uso do solo urbano. Dissertação (Mestrado em Geografia Humana) - Faculdade de Filosofia, Letras e Ciências Humanas, Universidade de São Paulo, São Paulo, 1979.

STARLING, H. O aparato repressivo do regime militar. In: SEMINÁRIO 1964: 50 ANOS DEPOIS, mar. 2014, São Paulo. Anais... São Paulo: Cebrap, mar. 2014 
TELLES, E.; SAFATLE, V. (Org.). O que resta da ditadura. São Paulo: Boitempo, 2010.

TOLEDO, C. N. 1964: o golpe contra as reformas e a democracia. Revista Brasileira de História, São Paulo, v. 24, n. 47, p. 13-28, 2004.

VERDI, E. F. Produção geográfica e ruptura crítica: a geografia uspiana entre 1964 e 1985. Dissertação (Mestrado em Geografia Humana) - Faculdade de Filosofia, Letras e Ciências Humanas, Universidade de São Paulo, São Paulo, 2016

VESENTINI, J. W. Memorial para concurso de Professor-Assistente. 1988.

VESENTINI, J. W. Geografia crítica e ensino. Revista Orientação, São Paulo, n. 6, 1985.

VESENTINI, J. W. A capital da geopolítica: um estudo geográfico sobre a implantação de Brasilia. Tese (Doutorado em Geografia Humana) - Faculdade de Filosofia, Letras e Ciências Humanas, Universidade de São Paulo, São Paulo, 1984. 